\title{
DIFFERENT TECHNIQUES OF EXTRACTION AND ANTIVIRAL ACTIVITIES OF QUERCETIN AGAINST VIRUSES SUCH AS CORONAVIRUS, INFLUENZA VIRUS, EBOLA VIRUS, ZIKA VIRUS, AND OTHER VIRUSES
}

\author{
DALILA ABDESSEMED* \\ Department of Agronomy, Laboratory LAPAPEZA, Institute of Veterinary and Agricultural Sciences, University of Batna, Batna, Algeria. \\ Email: dalila.abdessemed@univ-batna.dz
}

Received: 24 July 2020, Revised and Accepted: 28 September 2020

\begin{abstract}
Quercetin (QCT) is a flavonoid, existed as a pigment in various plants. It is a bioactive compound that has a favorable effect on human health. Our work concerns the selection of different rapid techniques for QCT extraction, published on the different scientific databases, as ultrasound-assisted enzymatic extraction process, supercritical $\mathrm{CO}_{2}$ extraction, microwave-assisted extraction and consists of researching the antiviral activity of QCT and derivatives against viruses such as coronaviruses, influenza virus, human respiratory syncytial virus, Epstein-Barr virus gastric tumor, anti-hepatitis B virus, Zika virus, and Ebola. Following this research, we found that this molecule has a broad-spectrum antiviral activity. Is it effective in controlling this new form of coronavirus, this devastating virus, which currently affects thousands of people?
\end{abstract}

Keywords: Ultrasound-assisted extraction, Microwave-assisted extraction, Antiviral activities, Coronavirus, Influenza virus.

(c) 2020 The Authors. Published by Innovare Academic Sciences Pvt Ltd. This is an open access article under the CC BY license (http://creativecommons. org/licenses/by/4. 0/) DOI: http://dx.doi.org/10.22159/ajpcr.2020.v13i12.39210

\section{INTRODUCTION}

Flavonoids represent a group of naturally occurring polyphenolic compounds that existed as a pigment in various fruits, vegetables, and pharmaceutical plants [1,2]. Polyphenols are known by their biological activity, including anti-viral, anti-oxidant, anti-bacterial, anti-cancer, vasodilatory, and anti-diabetic activities [3]. Quercetin (QCT) is one of the natural antioxidants [3] and the phenolic hydroxyl groups on the backbone of QCT can inhibit the oxidative damage caused by reactive oxygen species (ROS) [4,5]. Recent studies have also demonstrated the antiviral activity of these compounds against several of pathogens, including Ebola virus, hepatitis B virus (HBV), Chikungunya virus (CHIKV), hepatitis C virus (HCV), Mayaro virus, Epstein-Barr virus (EBV), and influenza virus (IAV) [6-8]. Our work concerns the selection of different rapid technics for QCT extraction, published on the different scientific databases, and we present several works on the antiviral effect of QCT and its derivatives against viruses.

\section{SOURCES OF QCT}

QCT (3, 3', 4', 5, 7pentahydroxyflavone) or Quercetol, Quertin, Xanthaurine (Fig. 1) is an organic compound of the flavonoid family [9]. It is a secondary metabolite present in some plants. Its role is to ensure the pigmentation of flowers and fruits [10]. It is known for its antiinflammatory actions; antihistamines, anti-oxidant, anti-bacterial, anti-cancer, vasodilatory, anti-diabetic activities, and tonics for the body [11-19]. It cannot be produced in the human body [20,21]. It is one of the most abundant dietary flavonoids found in fruits, vegetables, and grains (Fig. 2) [22,23].

The highest concentrations of flavonols were found in vegetables such as onions and broccoli, fruits such as apples, cherries, and berries (blueberries, cranberries, currants, etc.), and drinks such as tea and red wine. The USDA classifies the major food plants rich in QCT [24]. We find caper (Capparis spinosa) with 1808-328 mg/kg, lovage (Levisticum officinale) $1700 \mathrm{mg} / \mathrm{kg}$, hot pepper $14.7 \mathrm{mg} / 100 \mathrm{~g}$, black elderberry (Sambucus nigra) $42 \mathrm{mg} / 100 \mathrm{~g}$, Theobroma cacao $25 \mathrm{mg} / 100 \mathrm{~g}$, wild blueberries (Vaccinium myrtillus) $7.7 \mathrm{mg} / 100 \mathrm{~g}$, blackcurrants (Ribes nigrum) $5.7 \mathrm{mg} / 100 \mathrm{~g}$, raw broccoli (Brassica oleracea) $3.3 \mathrm{mg} / 100 \mathrm{~g}$, green tea $2.5 \mathrm{mg} / 100 \mathrm{~g}$, cherry (Prunus cerasus) $1.2 \mathrm{mg} / 100 \mathrm{~g}$, red wine $8.3 \mathrm{~g} / \mathrm{l}$, and apple $1.5 \mathrm{mg} / 100 \mathrm{~g}[9,21,24,25]$. The amount of QCT found varies considerably depending on the variety cultivated, the growing conditions, and the time of harvest. Here are some average values (Table 1).

\section{QCT EXTRACTION}

A process about an ultrasound-assisted enzymatic extraction using an ultrasonic bath and viscozyme applied for the recovery of total flavonoid content (TFC) from pomegranate peels was optimized using response surface methodology (RSM) by applying central composite rotatable design [26]. The optimum conditions obtained were an ultra-sonication time of $41.45 \mathrm{~min}$, enzyme concentration of $1.32 \mathrm{~mL} / 100 \mathrm{~mL}$, the incubation time of $1.82 \mathrm{~h}$, and incubation temperature of $44.85^{\circ} \mathrm{C}$, and the values of TFC at optimized conditions were $17.97 \mathrm{mg} \mathrm{QE} / \mathrm{g}$. Two strategies based on the solubility in supercritical $\mathrm{CO}_{2}$, in which $\mathrm{CO}_{2}$ plays different roles, are used [27] to make QCT particles by supercritical fluid technologies. The results showed that micronized QCT particles with a mean particle size of $1.0-1.5 \mu \mathrm{m}$ could be made through solution-enhanced dispersion by supercritical fluids process, in which $\mathrm{CO}_{2}$ worked as turbulent antisolvent. A new study aimed to investigate the effects of various solvents (water, aqueous-methanol, and aqueous-ethanol) and techniques maceration (M), ultrasound-assisted extraction (UAE), ohmic-assisted extraction (OAE), and decoction - infusion on extraction yield has been applied by Bahar et al. [28], the OAE with water as a solvent to score the highest rank in terms of overall efficiency. However, if the ranking is to be based on the isolation of bioactive materials at a reasonably short time, the UAE may be the preferred choice. Extracts obtained from two green extraction techniques, accelerated solvent extraction (ASE) and UAE, were evaluated [29] to inhibit the growth of bacteria implicated in alimentary pathologies and to avoid the oxidation reactions. Hydroalcoholic extracts obtained by UAE resulted to have higher antibacterial and antioxidant properties compared to aqueous extracts from ASE. A method of designing solvents for the optimal extraction of bioactive ingredients from natural resources was developed [30] using an alcohol-water binary solvent. Using the solubility parameter, the extraction efficiency of the bioactive ingredients was correlated 
with the solvent polarity. A reversed-phase high-performance liquid chromatography (HPLC) method has been developed and applied to determine resveratrol, QCT, quercitrin, and rutin content in several grape berries samples in a single analysis [31]. A study by microwaveassisted extraction was evaluated by Diana et al. [32]. The influence of the irradiation time and solvent concentration on the yield of phenolic compounds was studied. In conclusion, microwave technology presents some advantages such as required short times and small amounts of solvents in contrast with conventional extraction methods. A study, using RSM, was introduced [33] for the extraction of antioxidant compounds from plant biomass for the standardization of extraction of compounds of industrial interest. The optimal extraction conditions determined by full factorial design were $90 \mathrm{~min}$ at $80^{\circ} \mathrm{C}$ in water, $90 \mathrm{~min}$

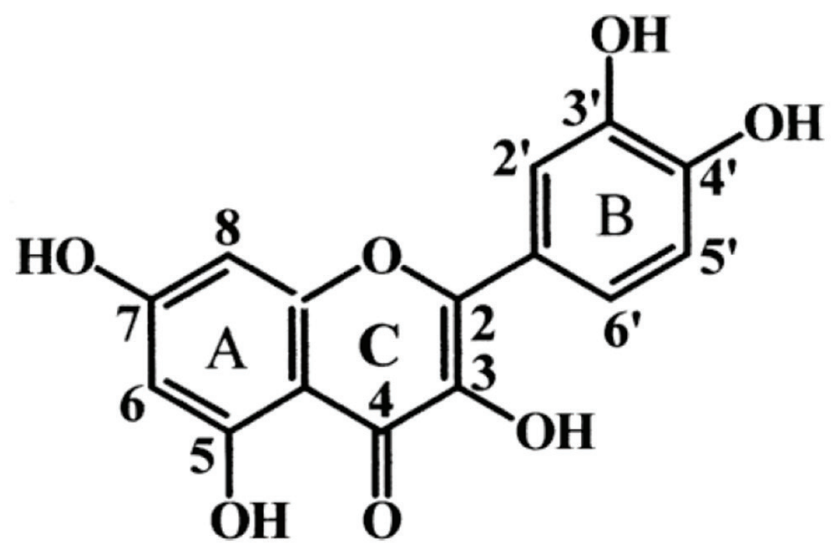

Fig. 1: Quercetin's chemical structure at $80^{\circ} \mathrm{C}$ in $40 \%$ ethanol, and $90 \mathrm{~min}$ at $80^{\circ} \mathrm{C}$ in $40 \%$ acetone. Different methods as M, ASE, and supercritical fluid extraction (SFE) coupled with ASE were evaluated to obtain plant extracts with high antioxidant capacity. The most beneficial conditions were calculated for methanol and water:ethanol (50:50) extracts derived from the combination of SFE and ASE methodologies [34]. A study was introduced to extract and determine the total contents of phenolic and flavonoid compounds as well as to identify and quantify some flavonoids from Sarang semut (Myrmecodia pendans) [35]. The optimum extracting parameters were determined as follows: Extraction time, $4 \mathrm{~h}$; ethanol/water composition, 80\%; and solvent to sample ratio, $50 \mathrm{~mL} / \mathrm{g}$. Under these optimal conditions, a yield of $13.82 \%$ was obtained. An extraction method based on the application of an extracting solvent lighter than water in the ternary component solvent (aqueous solution: extracting solvent: disperser solvent) system was developed using inverted dispersive liquid-liquid microextraction and (HPLC-ultraviolet) [36]. Another study conducted by Pazhanichamy et al. [37] aimed to isolate and quantify flavonoids from the ethanol extract of Costus igneus rhizome. QCT (Rf - 0.72, 0.794\%) and kaempferol (Rf - 0.35, 4.2\%) were quantified by high-performance thin-layer chromatography (HPTLC) using solvent ratio of toluene:ethyl acetate:acetic acid:methanol (2.00:7.00:0.25:0.25) and toluene:ethyl acetate:methanol:formic acid (6.00:3.00:0.20:0.40), respectively. An ultrasonic-assisted extraction process has been applied by Yingpeng et al. [38] for QCT extraction from Dendrobium officinale using HPLC as a separative method. The amount of QCT obtained was $2.50-2.59 \mu \mathrm{g} / \mathrm{g}$. A study investigated the application of subcritical water extraction (SWE) of QCT from onion skin. The maximum yield of QCT $(16.29 \pm 0.75 \mathrm{mg} / \mathrm{g}$ onion skin) was obtained at an extraction temperature of $165^{\circ} \mathrm{C}$, extraction time of 15 min, the mixture ratio of 1.5:2.5 for onion skin and diatomaceous earth. The SWE was compared with three conventional extraction methods

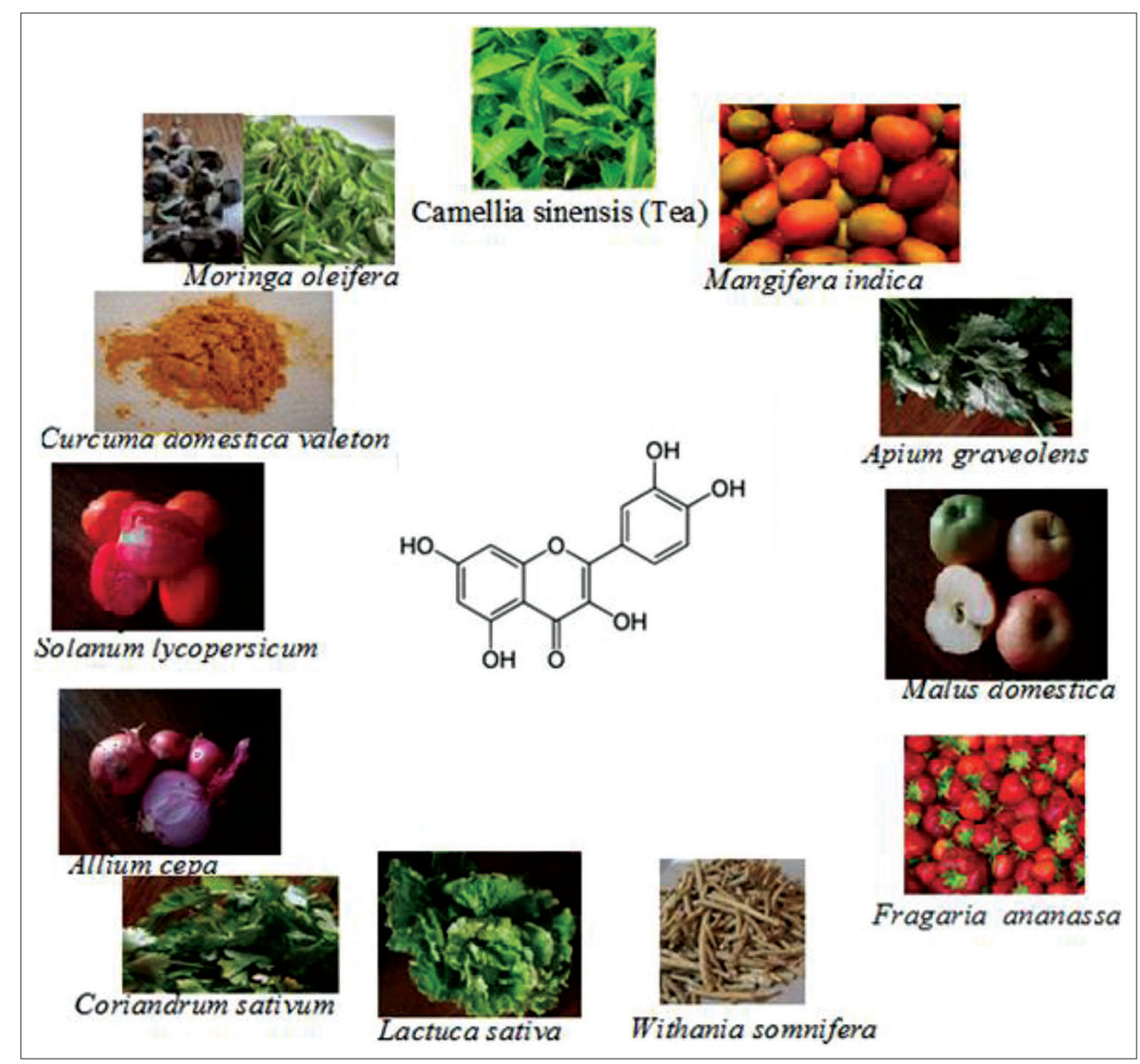

Fig. 2: The most common food plants that contain quercetin 
Table 1: Food plants rich in quercetin $(\mathrm{mg} / 100 \mathrm{~g})[24]$

\begin{tabular}{|c|c|c|}
\hline Plant name & Family & Teneur (mg/100 g) \\
\hline Allium fistulosum & Amaryllidaceae & / \\
\hline Allium cepa (red onions) & Liliaceae & 39.2 \\
\hline Apium graveolens & Apiaceae & / \\
\hline Asparagus officinalis & Asparagaceae & / \\
\hline Brassica oleracea var. italica (Broccoli) & Brassicaceae & 3.30 \\
\hline Brassica oleracea var. sabellica (Kale) & Brassicaceae & 22.6 \\
\hline Blueberries, raw & Ericaceae & 7.70 \\
\hline Calamus scipionum & Calamoideae & / \\
\hline Camellia sinensis (black) & Theaceae & 2.20 \\
\hline Camellia sinensis (green) & Theaceae & 2.50 \\
\hline Capparis spinosa & Capparaceae & $180.8-32.8$ \\
\hline Capsicum & Solanacées & 14.7 \\
\hline Centella asiatica & Apiaceae & / \\
\hline Coriandrum sativum & Apiaceae & / \\
\hline Curcuma domestica valeton & Zingiberaceae & / \\
\hline Cuscuta reflexa & Convolvulaceae & / \\
\hline Eruca vesicaria & Brassicaceae & 66.2 \\
\hline Foeniculum vulgare & Apiaceae & \\
\hline Fragaria ananassa & Rosaceae & / \\
\hline Glycyrrhiza glabra & Fabaceae & / \\
\hline Hypericum hircinum & Clusiaceae & / \\
\hline Hypericum perforatum & Hypericaceae & / \\
\hline Lactuca sativa & Asteraceae & 1.40 \\
\hline Levisticum officinale & Apiaceae & 70.0 \\
\hline Malus domestica & Rosaceae & 1.50 \\
\hline Mangifera indica & Anacardiaceae & / \\
\hline Momordica charantia & Cucurbitaceae & / \\
\hline Moringa oleifera & Moringa & / \\
\hline Morus alba & Moraceae & / \\
\hline Nasturtium officinale & Brassicaceae & 30.0 \\
\hline Ocimum sanctum & Lamiaceae & / \\
\hline Petroselinum crispum & Apiaceae & 1.00 \\
\hline Psoralea corylifolia & Fabaceae & / \\
\hline Ribes nigrum & Grossulariaceae & 5.70 \\
\hline Sambucus nigra & Adoxaceae & 420 \\
\hline Santalum album & Santalaceae & / \\
\hline Scallions & Liliaceae & 10.7 \\
\hline Solanum lycopersicum & Solanaceae & 0.80 \\
\hline Solanum nigrum & Solanaceae & \\
\hline Spinacia oleracea & Amaranthaceae & 4.00 \\
\hline Swertia chirayita & Gentianaceae & / \\
\hline Theobroma cacao & Sterculiacées & 25.0 \\
\hline Vaccinium myrtillus & Ericaceae & 7.70 \\
\hline Vaccinium oxycoccos & Ericaceae & / \\
\hline Vigna unguiculata & Fabaceae & 17.2 \\
\hline Vitis vinifera & Vitaceae & $8.30 \mathrm{mg} / \mathrm{L}$ \\
\hline Withania somnifera & Solanaceae & / \\
\hline
\end{tabular}

in terms of efficiency. The QCT yield by SWE was over eight-, six-, and four-fold greater than those obtained using the ethanol, methanol, and water-at-boiling-point extraction methods, respectively [39]. Optimized ultrasonic extraction conditions were applied to extract rutin and QCT from dried stalks of Euonymus alatus (Thunb.) Sieb. The application was shown to be highly efficient compared with classical methods [40]. A new study introduced by Dmitrienko et al. [41] based on the scanning electron microscopy micrographs provided evidence of more rapid opening of plant cells treated by UAE in contrast to M. State of the art methods of the extraction, preconcentration, and determination of QCT and other flavonoids are described. Some examples of QCT determination in biological fluids, food products, biologically active food supplements, pharmaceutical preparations, and plant samples are given. The extraction yields of QCT from Raphanus sativus L leaves have been determined using different methods, including $\mathrm{M}$, thermal digestion, Soxhlet, and UAE. UAE method at $50 \%$ of ultrasound intensity
(Frequency of 50/60 kHz) for 10 min in methanol proved to be the most efficient technique in QCT extracting (11.8\% yield) [42].

\section{IN CORONAVIRUS}

Coronaviruses (CoVs) belong to the subfamily Orthocoronavirinae in the family Coronaviridae order Nidovirales. There are four generations within the subfamily Orthocoronavirinae, namely, alphacoronavirus $(\alpha-\mathrm{CoV})$, betacoronavirus $(\beta-\mathrm{CoV})$, gammacoronavirus $(\gamma-\mathrm{CoV})$, and deltacoronavirus $(\delta-\mathrm{CoV})$. The $\mathrm{CoV}$ genome is an enveloped, positivesense, single-stranded RNA with a size varying between $26 \mathrm{~kb}$ and $32 \mathrm{~kb}$, the largest genome of known RNA viruses. Both $\alpha$ - and $\beta-\mathrm{CoV}$ genera are known to infect mammals, while $\delta$ - and $\gamma$-CoVs infect birds. Two recent outbreaks of viral pneumonia caused by $\beta$-CoVs are severe acute respiratory syndrome (SARS) and the Middle East respiratory syndrome (MERS) [43]. In 2002, an outbreak of SARS was first reported 
in China and then spread quickly worldwide, resulting in hundreds of deaths. In 2012, MERS first emerged in Saudi Arabia and subsequently spread to other countries. In both of these epidemics, the viruses likely originated from bats and then infected humans through other intermediate animal hosts, for example, the civet (Paguma larvata) for SARS-CoV and the camel for MERS-CoV. Besides, more recently coronavirus disease (COVID-19) in December 2019. SARS-CoV-2 (initially named 2019-nCoV) was detected in December 2019 from a cluster of patients in Wuhan, China, who developed pneumonia of unknown causes [44]. No vaccine or specific treatment is currently available. Since the antiviral activity of some flavonoids is known, [45] a flavonoid library to probe inhibitory compounds have applied against MERS-CoV 3C-like protease (3CLpro). Herbacetin, isobavachalcone, QCT 3- $\beta$-d-glucoside, and helichrysetin were found to block the enzymatic activity of MERS-CoV 3CLpro. In this way, another study [46] showed Chinese medical herbs that are commonly used in treating viral respiratory infections and also contain compounds that might directly inhibit 2019 novel coronavirus (2019-nCoV), an ongoing novel coronavirus that causes pneumonia. Recent studies [46] revealed that the genome sequence of SARS-CoV-2 is very similar to that of SARS-CoV. Here is a series of medicinal plants Chinese containing potential antiviral phytochemicals are screened against. The results of the analysis revealed that the top nine hits might serve as potential anti-SARS-CoV-2 lead molecules for further optimization and drug development process to combat COVID-19. An evaluation in vitro activities compounds in Houttuynia cordata (QCT, quercitrin, and rutin) conducted by Chiow et al. [47] against murine coronavirus and dengue virus indicated that they have much potential for the development of antiviral agents against coronavirus and dengue infection. In 2012 a series of QCT, derivatives are evaluated by Hye et al. [48] against the SARSassociated coronavirus (SARS-CoV, SCV) as well as HCV. An ethanolic extract and three flavones (apigenin, luteolin, and QCT) of Torreya nucifera [49] leaves were evaluated for SARS-CoV 3CLpro inhibition using fluorescence resonance energy transfer analysis (FRET). The ethanolic extract exhibited good SARS-CoV 3CLpro inhibitory activity $(62 \%$ at $100 \mu \mathrm{g} / \mathrm{mL})$, and apigenin, luteolin, and QCT inhibited 3CLpro activity with $\mathrm{IC}_{50}$ values of $28.0,20.2$, and $23.8 \mu \mathrm{moL}$, respectively. Chen et al. [50] identified a natural compound called QCT-3-b-galactoside as an inhibitor of the 3CLpro by molecular docking, surface plasmon resonance/FRET-based bioassays, and mutagenesis studies. This study not only reveals a new class of compounds as potential drug leads against the SARS virus but also provides a solid understanding of the mechanism of inhibition against the target enzyme.

\section{IN HUMAN RESPIRATORY SYNCYTIAL VIRUS (hRSV) ADHESION}

The hRSV is the main cause of acute lower respiratory tract infections in newborns, children, and the elderly. To date, treatments are only palliative and there is no vaccine available. Natural products show exceptional structural diversity and they have played a vital role in drug research. QCT is a flavonoid that presents several biological activities, including anti-hRSV role. QCT pentaacetate [51] could interact with F-protein with lower binding energy and better stability to block viral adhesion. These results show an alternative anti-hRSV strategy and contribute to drug discovery and development. Here, three types of flavonoids were investigated against the antiviral activity of CHIKV in vitro replication. Three compounds [52]: Silymarin, QCT, and kaempferol were evaluated for their in vitro antiviral activities against CHIKV using a CHIKV replicon cell line and a clinical isolate of CHIKV of Central/East African genotype. This study may have an important consequence for broadening the chance of getting effective antiviral for CHIKV infection. A study conducted by Weiss et al. showed that QCT $(3,30,40,5,7$-pentahydroxyflavone) [53] is an effective antioxidant in the prevention and treatment of viral upper respiratory illness (URI). It may be consumed as a supplement or within foods, such as broccoli, apples, berries, onions, and tea. In mice, it has been shown to counteract the increased URI susceptibility that is associated with exercise stress and to decrease viral replication, expression of cytokines, and airway hyperresponsiveness. The next work aimed to develop solid lipid microparticles (SLMs) as dry powders containing QCT for direct administration to the lung. Santo et al. [54] has investigated a formulation and aerosol delivery to the lung of solid lipid QCT microparticles as a potential active pharmaceutical ingredient for asthma therapy. Through this study, it was demonstrated SLM particle technology could be used to deliver this naturally derived flavonoid for the treatment of a range of respiratory diseases. In another study conducted by Serena et al. [55] confirmed that a QCT supplementation in doses of 500 and $1000 \mathrm{mg} /$ day for 12 weeks significantly increased plasma QCT levels with no reported side effects.

\section{IN IAVs}

IAVs cause seasonal pandemics and epidemics with high morbidity and mortality, which calls for effective anti-IAV agents. Influenza infection is a major public health threat. Drug resistance and side effects of chemical treatments have been observed, resulting in increased interest in alternative use of herbal medications for prophylaxis against this infection. Investigation of the antiviral and cytotoxic effect of QCT 3-glucoside (Q3G) from Dianthus superbus L. over IAV infection and replication was studied by Shivraj et al. [56]. IAV infection induced a higher ROS production; however, potentially reduced by Q3G treatment and significantly blocked virus infection-induced acidic vesicular organelles (AVO). Q3G from D. superbus showed potent antiviral activity against influenza $A$ and $B$ viruses with a suppressive effect on virus-induced cellular ROS generation and AVO formation. Thus, this study provided a new line of research for Q3G to develop possible natural anti-influenza drugs. The aim of the next study conducted by Parvaneh et al. [57] was to investigate the immunomodulatory properties of QCT-3-O- $\alpha$-L-rhamnopyranosidea isolated from Rapanea melanophloeos (L.) Mez. against IAVs. QCT-3-O- $\alpha$-L-rhamnopyranoside at $150 \mu \mathrm{g} / \mathrm{mL}$ decreased the viral titer. The expression of cytokines was also considerably affected by the compound treatment. Another study conducted by Wenjiao et al. [58] indicates that QCT showing inhibitory activity in the early stage of influenza infection provides a future therapeutic option to develop effective, safe, and affordable natural products for the treatment and prophylaxis of IAV infections. The next report [59] also showed that QCT 3-rhamnoside possessed antiviral activity against the influenza $\mathrm{A} / \mathrm{WS} / 33$ virus in vitro. This study shows the benefit of short-term QCT feedings on susceptibility to respiratory infection following exercise stress.

\section{IN EBV TUMOR GASTRIC}

EBV is a human gamma-1 herpesvirus that establishes lifelong latency in over $90 \%$ of the world's population. Antiviral effects of QCT were investigated against EBV-associated gastric carcinoma [8,60], those studies demonstrated that QCT has promising anti-HBV activity, mediated by the reduction of hepatitis B surface antigen (HBsAg) and hepatitis Be antigen (HBeAg) secretion as well as viral DNA level in vitro. Therefore, these results revealed the potential of QCT as an effective anti-HBV agent with low toxicity.

\section{ZIKA}

Zika virus (ZIKV) is a member of the Flaviviridae family and Flavivirus genus. The flavivirus genus is the largest among the Flaviviridae family with 53 different species. The first human cases of ZIKV infections were reported in Africa in 1950 and later in Asia but remained restricted to these regions until 2007 when a large outbreak occurred in Yap Island, the Federated States of Micronesia, followed by outbreaks in French Polynesia, New Caledonia, and the Cook Islands in 2013 and 2014. In May 2015, ZIKV spread across the Pacific Ocean and was introduced in Brazil, where it caused more than one million cases. As of May 2019, the virus rapidly spread to 84 countries, territories, or subnational areas and became a public health problem worldwide. Here, for the first time, it has discovered that QCT inhibits Zika NS2B-NS3pro [6]. Its inhibitory activity was quantified with $\mathrm{IC}_{50}$ of $26.0 \pm 0.1 \mu \mathrm{M}$; and Ki of $23.0 \pm 1.3 \mu \mathrm{M}$. A study conducted by Mariana et al. [61], about the anti-ZIKV effects of Q3G on Vero cells in vitro, demonstrated that Q3G exerts antiviral 
activity against ZIKV in both tissue culture and knockout mice and that post-exposure in vivo treatment with Q3G could have a beneficial effect. The following studies conducted by Roy et al., Hee-jung et al., and Zou et al. [62-64] demonstrate that several flavonoids Galangin, kaempferide, QCT, myricetin, and epigallocatechin gallate were found to reduce ZIKV, induced plaques, and viral RNA copies with negligible cytotoxic effects on host cells. Furthermore, inhibition of ZIKV propagation by flavonoids showed a structure-activity relationship. These results demonstrate flavonoids as inhibitors of ZIKV entry and NS2B-NS3 protease. Hence, these flavonoids could be used as potential bi-functional drugs for treating ZIKV infections.

\section{ANTIHEPATITE B AND OTHER VIRUSES}

A study conducted by Zhikui et al. [8] demonstrates that QCT reduces significantly HBsAg and HBeAg, secretion, and HBV genomic DNA levels in both cell lines. Recently, Parvez et al. [65] showed in vitro HBV activity of Guiera senegalensis leaves and identified QCT and other flavonoids by HPTLC. The two isolated bioactive compounds were identified as QCT and myricetin-3-0-rhamnoside. QCT significantly inhibited the synthesis of HBsAg and HBeAg by about $60 \%$ and $62 \%$. QCT 7-rhamnoside (Q7R) could be considered as a lead compound for the development [66] of anti-porcine epidemic diarrhea virus (antiPEDV) drugs to may be used during the early stage of PEDV replication and the structure-activity data of Q7R may usefully guideline to design another related antiviral agent [66]. However, the effects of QCT [67] feeding on the antioxidative status should be investigated to validate the health-protecting effects of QCT feeding in neonatal calves.

\section{EBOLA}

Ebola is a severe viral disease that spreads in West African countries, whose search for an effective drug is a necessity. The VP30 protein is known as an essential activator of transcription for the Ebola virus. Oleuropein, kaempferol, and QCT are bio-active components, originally from several plants, and which are known by their ability to inhibit viral transcription activators such as HIV. A study conducted by Kasmi [68] showed that the components are linked with the active sites of VP30 with a free energy score estimated near- $8 \mathrm{kcal} / \mathrm{mol}$ and an average distance of $1.8 / 10^{10} \mathrm{~m}$. It concludes that oleuropein, kaempferol, and QCT components may be an effective treatment for Ebola virus. Most promisingly, antiviral activity against two distinct species of Ebola virus was seen. This study serves as a proof of principle that Q3G has potential as a prophylactic against Ebola virus infection.

\section{CONCLUSION}

Following these various works, this molecule has a broad-spectrum antiviral activity. Is it effective in controlling this new form of COVID-19, this devastating virus, which currently affects thousands of people? QCT has inhibitory properties against coronavirus and maybe 1 day could offer an alternative, both preventive and curative, about the epidemic threat.

\section{ACKNOWLEDGMENTS}

Our thanks to CERIST National Online Documentation System (SNDL) for free access to a rich, unlimited database.

\section{CONFLICTS OF INTEREST}

The authors have declared that they have no conflicts of interest in this study.

\section{AUTHORS' FUNDING}

None.

\section{REFERENCES}

1. Mahmoud RS, Golnaz D. The application of continuous wavelet transform and least squares support vector machine for the simultaneous quantitative spectrophotometric determination of myricetin, kaempferol and quercetin as flavonoids in pharmaceutical plants. Spectrochim Acta A Mol Biomol Spectrosc 2016;152:443-52.

2. Sankhadip B, Dhrubajyoti S, Abhijit B, Subhash M. Natural flavonoids and its pharmaceutical importance. Pharma Rev 2018;61-75.

3. Tapas A, Sakarkarand D, Kakde RB. Flavonoids as nutraceuticals: A review. Trop J Pharm Res 2008;7:1089-99.

4. Boots AW, Haenen GR, Bast A. Health effects of quercetin: From antioxidant to nutraceutical. Eur J Pharmacol 2008;585:325-37.

5. Zhang M, Swarts SG, Yin L, Liu C, Tian Y, Cao Y, et al. Antioxidant properties of quercetin. Adv Exp Med Biol 2011;701:283-9.

6. Gary W, Shihua H, Vinayakumar S, Yuhai B, Majambu M, Chretien M, et al. Antiviral activity of quercetin-3- $\beta$-O-D-glucoside against zika virus infection. Virol Sin 2017;32:545-7.

7. Xiangguo Q, Kroeker A, Shihua H, Kozak R, Jonathan A, Mbikay M, et al. Prophylactic efficacy of quercetin 3--O-D-glucoside against ebola virus infection. Antimicrob Agents Chemother 2016;60:5182-8.

8. Zhikui C, Ge S, Wei G, Yayun H, Weihua S, Fei Z, et al. Inhibition of hepatitis $\mathrm{B}$ virus replication by quercetin in human hepatoma cell lines. Virol Sin 2015;30:261-8.

9. Alexander VA, Radhakrishnan A, Subramani P. Overviews of biological importance of quercetin: A bioactive flavonoid. Pharmacogn Rev 2016;10:84-9.

10. Shakya AK. Medicinal plants: Future source of new drugs. Int J Herb Med 2016;59:59-64.

11. Conquer JA, Maiani G, Azzini E, Raguzzini A, Holub BJ. Supplementation with quercetin markedly increases plasma quercetin concentration without effect on selected risk factors for heart disease in healthy subjects. J Nutr 1998;128:593-7.

12. Kumar S, Pandey AK. Chemistry and biological activities of flavonoids: An overview. Sci World J 2013;16:27-50

13. Egert S, Bosy-Westphal A, Seiberl J, Kürbitz C, Settler U, PlachtaDanielzik S, et al. Quercetin reduces systolic blood pressure and plasma oxidised low-density lipoprotein concentrations in overweight subjects with a high-cardiovascular disease risk phenotype: A double-blinded, placebo-controlled cross-over study. Br J Nutr 2009;102:1065-74.

14. Edwards RL, Lyon T, Litwin SE, Rabovsky A, Symons JD, Jalili T. Quercetin reduces blood pressure in hypertensive subjects. J Nutr 2007; 137:2405-11.

15. Zahedi M, Ghiasvand R, Feizi A, Asgari G, Darvish L. Does quercetin improve cardiovascular risk factors and inflammatory biomarkers in women with Type 2 diabetes: A double-blind randomized controlled clinical trial. Int J Prev Med 2013;4:777-85.

16. Hahn S, Pace-Asciak CR, Diamandis EP, Soleas G, Goldberg DM. The red wine phenolics trans-resveratrol and quercetin block human platelet aggregation and eicosanoid synthesis: Implications for protection against coronary heart disease. Clin Chim Acta 1995;235:207-19.

17. Wang L, Lee IM, Zhang SM, Blumberg JB, Buring JE, Sesso HD. Dietary intake of selected flavonols, flavones, and flavonoid-rich foods and risk of cancer in middle-aged and older women. Am J Clin Nutr 2009;89:905-12

18. Rogerio AP, Sá-Nunes A, Faccioli LH. The activity of medicinal plants and secondary metabolites on eosinophilic inflammation. Pharmacol Res 2010;62:298-307.

19. Hubbard GP, Wolffram S, de Vos R, Bovy A, Gibbins JM, Lovegrove JA. Ingestion of onion soup high in quercetin inhibits platelet aggregation and essential components of the collagen-stimulated platelet activation pathway in man: A pilot study. Br J Nutr 2006;96:482-8.

20. Dabeek WM, Marra MV. Dietary quercetin and kaempferol: Bioavailability and potential cardiovascular-related bioactivity in humans. Nutrients 2019;11:2288.

21. Manach C, Scalbert A, Morand C, Remesy C, Jimenez L. Polyphenols: Food sources and bioavailability. Am J Clin Nutr 2004;79:727-47.

22. Brull V, Burak C, Stoffel-Wagner B, Wolffram S, Nickenig G, Müller C, et al. Effects of a quercetin-rich onion skin extract on $24 \mathrm{~h}$ ambulatory blood pressure and endothelial function in overweight-toobese patients with (pre-)hypertension: A randomised double-blinded placebo-controlled cross-over trial. Br J Nutr 2015;114:1263-77.

23. McAnlis GT, McEneny J, Pearce J, Young IS. Absorption and antioxidant effects of quercetin from onions, in man. Eur J Clin Nutr 1999;53:92-6.

24. Nutrient Data Laboratory Food Composition Laboratory, U.S. Department of Agriculture. USDA Database for the Flavonoid Content of Selected Food. United States: Nutrient Data Laboratory Food Composition Laboratory, U.S. Department of Agriculture; 2007.

25. Formica JV, Regelson W. Review of the biology of quercetin and related bioflavonoids. Food Chem Toxicol 1995;33:1061-80. 
26. Sukanya N, Nandan S. Optimization of ultrasound assisted enzymatic extraction of polyphenols from pomegranate peels based on phytochemical content and antioxidant property. J Food Meas Charact 2018;12:1734-43.

27. Can Q, Carlfors J, Turner C. Carotenoids particle formation by supercritical fluid technologies. Chin J Chem Eng 2009;17:344-9.

28. Bahar S, Akram S, Leila RN, Mehrdad N, Mohammad A. Phenolic content and antioxidant activity of flixweed (Descurainia sophia) seeds extracts: Ranking extraction systems based on fuzzy logic method. Sustain Chem Pharm 2020;16:100-245.

29. Poveda M, Loarce L, Alarcón M, Díaz-Maroto MC, Alañón ME. Revalorization of winery by-products as source of natural preservatives obtained by means of green extraction techniques. Ind Crops Prod 2018;112:617-25.

30. Kim JM, Chang SM, Kim IH, Kim YE, Kim WS. Design of optimal solvent for extraction of bioactive ingredients from mulberry leaves. Biochem Eng J 2007;37:271-78.

31. Palomino OM, Gómez-Serranillos P, Slowing K, Carretero E, Villar A. Study of polyphenols in grape berries by reversed-phase highperformance liquid chromatography. J Chromatogr A 2000;870:449-51.

32. Muñiz-Márquez DB, Wong-Paz JE, Contreras-Esquivel JC, RodriguezHerrera R, Aguilar CN. Extraction of phenolic compounds from Coriandrum sativum L. and Amaranthus hybridus L. by microwave technology. In: Polyphenols in Plants: Isolation, Purification and Extract Preparation. $2^{\text {nd }}$ ed. Netherlands: Elsevier; 2019. p. 185-90.

33. Casagrande M, Juliano Z, Wagner A, Cleverson B, Maneck CR. Influence of time, temperature and solvent on the extraction of bioactive compounds of Baccharis dracunculifolia: In vitro antioxidant activity, antimicrobial potential, and phenolic compound quantification. Ind Crops Prod 2018;1251:207-19.

34. Kukula-Koch W, Aligiannis N, Halabalaki M, Skaltsounis AL, Kalpoutzakis E. Influence of extraction procedures on phenolic content and antioxidant activity of Cretan barberry herb. Food Chem 2013;138:406-13.

35. Adam ME, Novy SK, Yeshitila AT, Suryadi I, Yi-Hsu J. Extraction, identification and quantitative HPLC analysis of flavonoids from Sarang Semut (Myrmecodia pendan). Ind Crops Prod 2013;41:392-6.

36. Ranjbari E, Biparva P, Hadjmohammadi MR. Utilization of inverted dispersive liquid-liquid microextraction followed by HPLC-UV as a sensitive and efficient method for the extraction and determination of quercetin in honey and biological samples. Talanta 2012;8930:117-23.

37. Pazhanichamy K, Kunthavai B, Bhuvaneswari K, Aashefa K, Naina M, Kaliaperumal R. Isolation and quantification of flavonoids from ethanol extract of Costus igneus rhizome (CiREE) and impact of CiREE on hypoglycaemic, electron microscopic studies of pancreas in streptozotocin (STZ)-induced diabetic rats. Biomed Prev Nutr 2013:3:285-97.

38. Yingpeng Z, Jiangliu Y, Chunyan J, Jinfeng T, Lei Z, Yan C, et al. Optimization of quercetin extraction method in Dendrobium officinale by response surface methodology. Heliyon 2019;5:2374.

39. Min JK, Chan IC, Sang WC, Myong SC. Subcritical water extraction of flavonol quercetin from onionskin. J Food Eng 2011;102:327-33.

40. Yang Y, Zhang F. Ultrasound-assisted extraction of rutin and quercetin from Euonymus alatus (Thunb.) Sieb. Ultrason Sonochem 2008;15:308-13.

41. Dmitrienko SG, Kudrinskaya VA, Apyari VV. Methods of extraction, preconcentration, and determination of quercetin. $\mathrm{J}$ Anal Chem 2012;67:299-311.

42. Niusha S, Shabnam M, Massoud A. Comparison of different methods in quercetin extraction from leaves of Raphanus sativus L. Pharm Sci 2017;23:59-65.

43. Li H, Shang-Ming L, Xiao-Hua Y, Shi-Lin T, Chao-Ke T. Coronavirus disease 2019 (COVID-19): Current status and future perspective. Int J Antimicrob Agents 2020;55:10591.

44. Seri J, Hyojin K, Suwon K, Dong HS, Mi-Sun K. Characteristics of flavonoids as potent MERS-CoV 3C-like protease inhibitors. Chem Biol Drug Des 2019;94:2023-30.

45. Zhang D, Wu K, Zhang X, Deng S, Peng B. In silico screening of Chinese herbal medicines with the potential to directly inhibit 2019 novel coronavirus. J Integr Med 2020;18:152-8.

46. Muhammad TU, Safar MA, Mubarak AA, Chen LL. Structural basis of SARS-CoV-2 3CLpro and anti-COVID-19 drug discovery from medicinal plants. J Pharm Anal 2020;10:313-9.

47. Chiow KH, Phoon MC, Thomas P, Benny KH, Vincent TC. Evaluation of antiviral activities of Houttuynia cordata Thunb. Extract, quercetin, quercetrin and cinanserin on murine coronavirus and dengue virus infection. Asian Pac J 2016;1:1-7.

48. Park HR, Yoon H, Kim MK, Lee SD, Chong Y. Synthesis and antiviral evaluation of 7-o-arylmethylquercetin derivatives against SARSassociated coronavirus $(\mathrm{S} ; \mathrm{CV})$ and hepatitis $\mathrm{C}$ virus $(\mathrm{HCV})$. Arch Pharm Res 2012;35:77-85.

49. Young BR, Hyung JJ, Jang HK, Young MK, Ji-Young P, Doman K, et al. Biflavonoids from Torreya nucifera displaying SARS-CoV 3CLpro inhibition. Bioorg Med Chem 2010;18:7940-47.

50. Chen L, Li J, Cheng L, Liu H, Xu W, Gang C, et al. Binding interaction of quercetin-3-b-galactoside and its synthetic derivatives with SARSCoV 3CLpro: Structure-activity relationship studies reveal salient pharmacophore features. Bioorg Med Chem 2006;14:8295-306.

51. Lopes BR, da Costa MF, Ribeiro AG, da Silva TF, Alves KT. Quercetin pentaacetate inhibits in vitro human respiratory syncytial virus adhesion. Virus Res 2020;276:197805.

52. Lani R, Pouya H, Chun WC, Moghaddam E, Jang HC, Rausalu K, et al. Antiviral activity of silymarin against chikungunya virus. J Nat Sci Rep 2015;5:11421.

53. Weiss JR, Belachew T, Seth MB. Complementary and integrative treatments upper respiratory infection. Otolaryngol Clin N Am 2013;46:335-44.

54. Santo S, Mehra H, Vanessa L, Trotta V, Young PM, Traini D. Quercetin solid lipid microparticles: A flavonoid for inhalation lung delivery. Eur J Pharm Sci 2013;49:278-85

55. Serena AH, Henson DA, Melanie DA, Jin F, Nieman DC. Quercetin supplementation and upper respiratory tract infection: A randomized community clinical trial. Pharmacol Res 2010;62:237-42.

56. Shivraj HN, Doo HK, Arti N, Gyun SP, Guoyin K. Probing the effect of quercetin 3-glucoside from Dianthus superbus L against influenza virus infection-in vitro and in silico biochemical and toxicological screening. Food Chem Toxicol 2020;135:110985

57. Parvaneh M, Ali AM, Fotouhi F, Heidarzadeh M, Abimbola OA, Jacobus NE, et al. Immunomodulatory properties of quercetin-3-O- $\alpha$ L-rhamnopyranoside from Rapanea melanophloeos against influenza a virus. Complement Alternat Med 2018;18:184.

58. Wenjiao W, Richan L, Xianglian L, Jian H, Shibo J, Shuwen L, et al. Quercetin as an antiviral agent inhibits influenza a virus (IAV) entry. Viruses 2016;8:6.

59. Choi HJ, Song JH, Kwon DH. Quercetin 3-rhamnoside exerts antiinfluenza a virus activity in mice. Phytother Res 2011;26:462-4.

60. Minjung L, Myoungki S, Eunhyun R, Su SY, Gwang KJ, Byung WK, et al. Quercetin-induced apoptosis prevents EBV infection. Oncotarget 2015;6:12603-24.

61. Mariana B, Boivin G. Antiviral agents in development for zika virus infections. Pharmaceuticals 2019;12:101.

62. Roy A, Liangzhong L, Jianxing S. Identification of quercetin from fruits to immediately fight zika (quercetin inhibits zika NS2B-NS3 protease). BioRxiv 2016.

63. Hee-jung L, Nguyen TT, Nahyun MK, Jun-Seong P. Inhibitory effect of flavonoids against NS2B-NS3 protease of ZIKA virus and their structure activity relationship. Biotechnol Lett 2017;39:415-21.

64. Zou M, Hongmiao L, Jingyan L, Xingang Y, Chen Y, Changwen $\mathrm{K}$, et al. Structure-activity relationship of flavonoid bifunctional inhibitors against zika virus infection. Biochem Pharmacol 2020;6:113962.

65. Parvez MK, Al-Dosari MS, Arbab AH, Al-Rehaily AJ, Abdelwahid MA. Bioassay-guided isolation of anti-hepatitis B virus flavonoid myricetin3-O-rhamnoside along with quercetin from Guiera senegalensis leaves. Saudi Pharm J 2020;28:550-9.

66. Hwa-Jung C, Jin-Hee K, Choong-Hwan L, Young-Joon A, JaeHyoung S, Seung-Hwa B, et al. Antiviral activity of quercetin 7-rhamnoside against porcine epidemic diarrhea virus. Antiviral Res 2009;81:77-81.

67. Maciej J, Schäff CT, Kanitz E, Tuchscherer A, Bruckmaier RM, Wolffram S, et al. Bioavailability of the flavonol quercetin in neonatal calves after oral administration of quercetin aglycone or rutin. J Dairy Sci 2015;98:3906-17.

68. Kasmi Y. In silico study of the inhibitory effects of oleuropein, kaempferol, and quercetin on the VP30 protein from Ebola virus. Int $\mathrm{J}$ Innov Appl Stud 2014;8:1566-73. 